\title{
Flurbiprofen benzyl nitrate (NBS-242) inhibits the growth of A-43 I human epidermoid carcinoma cells and targets $\beta$-catenin
}

This article was published in the following Dove Press journal:

Drug Design, Development and Therapy

8 May 2013

Number of times this article has been viewed

\author{
Niharika Nath ${ }^{1,2}$ \\ Xiaoping Liu $^{3}$ \\ Lloydine Jacobs' \\ Khosrow Kashfi ${ }^{1,3}$ \\ 'Department of Physiology, \\ Pharmacology, and Neuroscience, \\ Sophie Davis School of Biomedical \\ Education, City University of \\ New York Medical School, New \\ York, NY, USA; '2Department of \\ Life Sciences, New York Institute \\ of Technology, New York, NY, USA; \\ ${ }^{3}$ Division of Cancer Prevention, \\ Department of Medicine, Stony \\ Brook University, Stony Brook, \\ NY, USA
}

Background: The Wnt/ $\beta$-catenin/T cell factor (TCF) signaling pathway is important in the development of nonmelanoma skin cancers (NMSCs). Nitric-oxide-releasing nonsteroidal antiinflammatory drugs (NO-NSAIDs) are chemopreventive agents consisting of a traditional NSAID attached to an NO-releasing moiety through a chemical spacer. Previously we showed that an aromatic spacer enhanced the potency of a particular NO-NSAID compared to an aliphatic spacer. Methods: We synthesized an NO-releasing NSAID with an aromatic spacer (flurbiprofen benzyl nitrate, NBS-242), and using the human skin cancer cell line A-431, we evaluated its effects on cell kinetics, Wnt/ $\beta$-catenin, cyclin D1, and caspase-3.

Results: NBS-242 inhibited the growth of A-431 cancer cells, being $\sim 15$-fold more potent than flurbiprofen and up to 5-fold more potent than NO-flurbiprofen with an aliphatic spacer, the half maximal inhibitory concentrations $\left(\mathrm{IC}_{50}\right)$ for growth inhibition being $60 \pm 4 \mu \mathrm{M}, 320 \pm 20 \mu \mathrm{M}$, and $880 \pm 65 \mu \mathrm{M}$ for NBS-242, NO-flurbiprofen, and flurbiprofen, respectively. This effect was associated with inhibition of proliferation, accumulation of cells in the $\mathrm{G}_{0} / \mathrm{G}_{1}$ phase of the cell cycle, and an increase in apoptotic cell population. NBS-242 cleaved $\beta$-catenin both in the cytoplasm and the nucleus of A-431 cells. NBS-242 activated caspase- 3 whose activation was reflected in the cleavage of procaspase- 3 . To test the functional consequence of $\beta$-catenin cleavage, we determined the expression of cyclin D1, a Wnt-response gene. NBS-242 reduced cyclin D1 levels in a concentration dependent manner.

Conclusion: These findings establish a strong inhibitory effect of NBS-242 in A-431 human epidermoid carcinoma cells. NBS-242 modulates parameters that are important in determining cellular mass.

Keywords: flurbiprofen, nitric oxide, $\beta$-catenin, chemoprevention, skin cancer

\section{Introduction}

In the USA, nonmelanoma skin cancers (NMSCs) are increasing by about one million new cases annually. ${ }^{1}$ The $\mathrm{Wnt} / \beta$-catenin/T cell factor (TCF) signaling pathway has been shown to be important in the development of many cancers including colon, prostate, leukemia, and others. The $\mathrm{Wnt} / \beta$-catenin pathways are also implicated in the development of malignancy in NMSCs such as squamous cell carcinoma (SCC) of the skin $^{2,3}$ and basal cell carcinoma (BCC). ${ }^{4}$ Mouse models of induced skin tumors have provided evidence of constitutive activation of $\beta$-catenin/TCF signaling. ${ }^{5} \beta$-catenin is a multifunctional protein that controls a number of cell activities, both at the membrane and the nuclear level. In the nucleus, $\beta$-catenin interacts with the TCF family of transcription factors. Elevated $\beta$-catenin/TCF-4 signaling is correlated with activation of its downstream target cyclin D1 and accelerated entry from the $\mathrm{G}_{1}$ phase into the
Correspondence: Khosrow Kashfi Department of Physiology,

Pharmacology, and Neuroscience, City University of New York Medical School, I38th Street and Convent Avenue, New York, NY, USA 10031

$\mathrm{Tel}+\mathrm{I} 212650664 \mathrm{I}$

Fax +I 2126507692

Email kashfi@med.cuny.edu 
$\mathrm{S}$ phase of the cell cycle. The upregulation of cyclin D1 is generally accepted as the basis for $\beta$-catenin's proliferative and oncogenic effect.

Nonsteroidal anti-inflammatory drugs (NSAIDs) are considered to be the prototypical cancer chemopreventive agents. ${ }^{6}$ A number of randomized, double-blind trials of aspirin against colorectal adenomas have established their chemopreventive effect. ${ }^{7-9}$ Recently, Rothwell et al ${ }^{10}$ reported that even daily use of low dose aspirin resulted in reductions in cancer incidence and mortality. Moreover, they also reported that aspirin prevented distant metastasis. ${ }^{11}$ For skin cancer, NSAIDs have been shown to have a protective effect against $\mathrm{SCC}$ and $\mathrm{BCC} .{ }^{12}$ Interestingly, the data suggested that a shorter duration of use offered a better protective effect than a longer duration of use. Recently, it was shown that celecoxib, an NSAID which selectively inhibits the enzyme cyclo-oxygenase- 2 , may be effective for prevention of SCCs and BCCs in individuals who have extensive actinic damage and are at high risk for development of nonmelanoma skin cancers. ${ }^{13}$ A recent study concluded that long-term use ( $>5$ years) of NSAIDs, especially aspirin, was associated with a significantly decreased risk of developing cutaneous melanoma. ${ }^{14}$ However, regular NSAID use may lead to serious side effects encompassing the gastrointestinal, renal, and cardiovascular systems. ${ }^{15-17}$ These potential life-threatening side effects are limiting to the widespread use of NSAIDs as potential chemopreventive agents.

Nitric-oxide-releasing NSAIDs (NO-NSAIDs) are an emerging new class of chemopreventive agents. They consist of a traditional NSAID attached to an NO-releasing moiety through a chemical spacer. Animal ${ }^{18,19}$ and human ${ }^{20,21}$ studies have shown that many NO-NSAIDs are safer to the gastrointestinal mucosa than the parent NSAID. We had previously shown that an aromatic spacer enhanced the potency of a particular NO-NSAID compared to an aliphatic spacer. ${ }^{22}$ At the cellular level, our previous studies have also demonstrated that the chemopreventive effects may be mediated through proapoptotic and antiproliferative effects of NO-NSAIDs in various cancer cell lines of different cell types. ${ }^{23,24}$ Hence, for these studies, we synthesized an NO-releasing arylpropionic acid NSAID, comprising an aromatic spacer and evaluated it against the human skin cancer cell line, A-431 which expresses $\beta$-catenin. In this study, we compared the effects of the NSAID flurbiprofen, NO-releasing-flurbiprofen containing an aliphatic spacer, and the newly synthesized flurbiprofen benzyl nitrate (FBN, NBS-242), which has an aromatic spacer on cell growth inhibition. The effect of FBN on cell proliferation, apoptosis, and cell cycle was examined with a focus on the Wnt pathway components.

\section{Materials and methods Reagents and cell culture}

NO-flurbiprofen (4-(nitrooxy)butyl 2-(2-fluoro-[1,1'biphenyl]-4-yl)propanoate) and flurbiprofen benzyl nitrate (4-O-[2-(3-fluoro-4-phenyl)phenyl propionyl]4-hydroxybenzyl nitrate, NBS-242) (Figure 1) were synthesized and purified as described previously. ${ }^{25}$ Stock solutions $(100 \mathrm{mM})$ were made in dimethyl sulfoxide (DMSO); the final DMSO concentration was adjusted in all media to $1 \%$. Flurbiprofen and other fine chemicals were obtained from Sigma-Aldrich (St Louis, MO, USA). A-431 human epidermoid carcinoma (ATCC, Manassas, VA, USA) cells were grown in Dulbecco's Modified Eagle Medium (DMEM) supplemented with 10\% fetal bovine serum (FBS), $100 \mathrm{unit} / \mathrm{mL}$ of penicillin, and $100 \mu \mathrm{g} / \mathrm{mL}$ of streptomycin in a humidified atmosphere containing $5 \% \mathrm{CO}_{2}$ and $95 \%$ air at $37^{\circ} \mathrm{C}$.

\section{Determination of cell viability by MTT assay}

Cell growth inhibition was measured using an MTT kit (Roche, Indianapolis, IN, USA). A-431 cells were plated at a density of 7000 cells/well in a 96-well plate. After overnight incubation, cells were treated with vehicle or various concentrations of the test compounds for 24 hours after which viable cells were quantified according to the

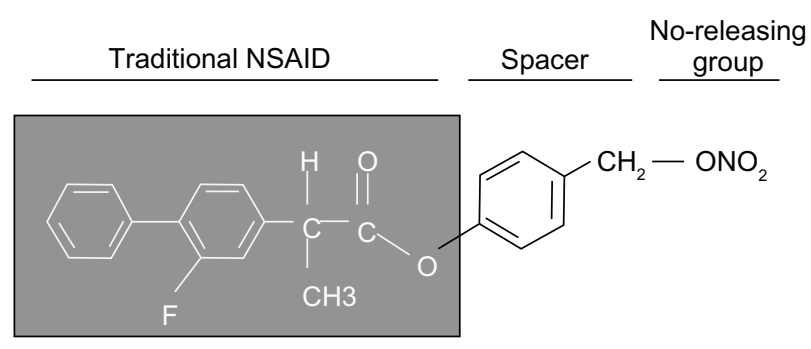

Flurbiprofen benzyl nitrate

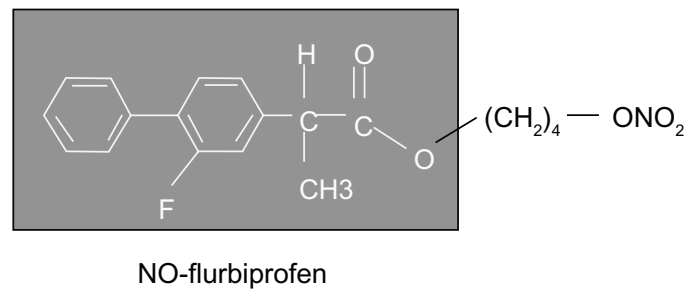

Figure I Structural features of flurbiprofen, NO-flurbiprofen, and flurbiprofen benzyl nitrate.

Abbreviations: NO, nitric oxide; NSAID, nonsteroidal anti-inflammatory drug. 
manufacturer's instructions. Growth inhibition was expressed as percentage of the corresponding control.

\section{Proliferating cell nuclear antigen (PCNA) staining for cell proliferation}

A-431 cells (8000 cells/well) were treated for 24 hours with various concentrations of FBN. Cell proliferation was assessed by measuring the levels of PCNA using a PCNA enzyme-linked immunosorbent assay kit (Calbiochem, La Jolla, CA, USA), in accordance with the manufacturer's protocol.

\section{4,6-diamidino-2-phenylindole (DAPI) staining for cell death analysis}

Chromatin condensation for detection of apoptosis was determined by DAPI fluorescence. Cells were cultured in the growth medium in the presence or absence of FBN for 24 hours. Cells were washed three times with phosphatebuffered solution (PBS), fixed in a 3.7\% formaldehyde solution for 10 minutes, fixed once in $1 \mathrm{~mL}$ of methanol, stained, and mounted in a fluid containing $2 \mathrm{mg} / \mathrm{mL}$ DAPI (Oncor Inc, Gaithersburg, MD, USA). Results were determined by visual observation of nuclear morphology via fluorescence microscopy.

\section{Cell cycle analysis}

A-431 cells were treated for 24 hours with various concentrations of FBN. Cell cycle phase distributions of control and treated cells were obtained using a Coulter Profile XL, (Beckman Coulter, Inc., Fullerton, CA, USA) equipped with a single argon ion laser. For each subset, $>10,000$ events were analyzed. All parameters were collected in list mode files. Data were analyzed on a Coulter XL Elite Workstation, (Beckman Coulter, Inc.) using the software programs Multigraph and Multicycle. Cells $\left(0.5 \times 10^{6}\right)$ were fixed in $100 \%$ methanol for 10 minutes at $-20^{\circ} \mathrm{C}$, pelleted $(5000 \mathrm{rpm}$ for 10 minutes at $4^{\circ} \mathrm{C}$ ), resuspended, and incubated in PBS containing $1 \%$ FBS $/ 0.5 \%$ NP-40 on ice for 5 minutes. Cells were washed again in $500 \mu \mathrm{L}$ of $\mathrm{PBS} / 1 \% \mathrm{FBS}$ containing $40 \mu \mathrm{g} / \mathrm{mL}$ propidium iodide (used to stain for DNA) and $200 \mu \mathrm{g} / \mathrm{mL}$ RNase type IIA, and analyzed within 30 minutes by flow cytometry. The percentage of cells in the $\mathrm{G}_{0} / \mathrm{G}_{1}, \mathrm{G}_{2} / \mathrm{M}$, and $\mathrm{S}$ phases was determined from DNA content histograms.

\section{Cytoplasmic and nuclear protein extraction}

To obtain nuclear protein extracts, cell pellets were resuspended in 500- $\mu \mathrm{L}$ lysis-buffer I (10 mM Tris-HCl [ph 7.4], $10 \mathrm{mM}$
$\mathrm{NaCl}, 3 \mathrm{mM} \mathrm{MgCl}$, and $0.5 \% \mathrm{NP}-40$ ), incubated for 5 minutes on ice, and centrifuged at $3200 \mathrm{rpm}$ for 5 minutes. Nuclei were then washed with washing buffer (10 mM Tris- $\mathrm{HCl}$ [pH 7.4], $10 \mathrm{mM} \mathrm{NaCl}$, and $3 \mathrm{mM} \mathrm{MgCl}_{2}$ ), resuspended in lysis-buffer II (20 mM Tris-HCl [pH 7.4], $40 \mathrm{mM}$ Na-pyrophosphate, $50 \mathrm{mM} \mathrm{NaF}, 5 \mathrm{mM} \mathrm{MgCl}_{2}, 20 \mathrm{mM}$ ethylenediaminetetraacetic acid [EDTA], 1\% Triton-X-100, and 0.5\% SDS, $0.1 \mathrm{mM}$ phenylmethylsulfonyl fluoride [PMSF]), sonicated, and centrifuged at $14,000 \mathrm{rpm}$ for 10 minutes. The supernatant was diluted by the addition of one vol lysis buffer III (20 mM HEPES-KOH, pH 7.4, 0.2 mM EDTA, 0.5 mM PMSF, and $2 \mathrm{mM}$ dithiothreitol). Glycerol was added to obtain a final concentration of $20 \%$, and aliquots were stored at $-80^{\circ} \mathrm{C}$. Lastly, $50 \mu \mathrm{g}$ of soluble extracts and $30 \mu \mathrm{g}$ of nuclear extracts were separated by sodium dodecyl sulfate polyacrylamide gel electrophoresis (SDS-PAGE) followed by immunoblotting according to standard protocols.

\section{Antibodies}

Primary mouse monoclonal antibodies were against the following at the dilutions indicated: $\beta$-catenin, 1:1000 (BD Transduction Laboratories, San Jose, CA, USA); TCF-4, 1:500 (Upstate Biotechnology, Lake Placid, NY, USA); $\alpha$-tubulin, 1:1000 (Santa Cruz Biotechnology, Santa Cruz, CA, USA); Cox-2, 1:2000 (Cayman Chemicals, Ann Arbor, MI, USA), and rabbit polyclonal anti-cyclin D1, 1:1000 (Upstate Biotechnology). Secondary antibodies conjugated to horseradish peroxidase (1:4000) were from Sigma-Aldrich. Immunoreactive protein was detected by using chemiluminescence (Pierce Chemicals, Rockford, IL, USA).

\section{Statistics}

Data are presented as the mean \pm standard error of the mean, with sample sizes as indicated in figure legends. Comparisons between groups were performed using a one-way analysis of variance followed by a Student's $t$-test; $P<0.05$ was considered significant.

\section{Results \\ FBN strongly inhibits the growth of $A-43$ I cells}

We examined the growth inhibitory activities of FBN, NO-flurbiprofen, and flurbiprofen (their structures are presented in Figure 1) by an MTT assay in the A-431 human epidermoid carcinoma cell line. For the initial growth inhibition study, a wide range of doses of the three compounds, including up to $1000 \mu \mathrm{M}$ for flurbiprofen, were used in order to obtain observable readouts for all the compounds. 
After treatment of cells for 24 hours, the percent inhibition was determined for the various concentrations examined. Overall, all three compounds inhibited cell growth in a concentration-dependent manner. Among the three compounds, flurbiprofen exhibited a moderate inhibitory effect on cell growth, the aliphatic NO-flurbiprofen strongly inhibited growth, whereas the aromatic NO-flurbiprofen (FBN) was significantly more potent (Figure 2). The half maximal inhibitory concentration $\left(\mathrm{IC}_{50}\right)$ values determined for each compound were $880 \pm 65 \mu \mathrm{M}, 320 \pm 20 \mu \mathrm{M}$, and $60 \pm 4 \mu \mathrm{M}$ for flurbiprofen, aliphatic NO-flurbiprofen, and FBN, respectively. The ratio of the $\mathrm{IC}_{50} \mathrm{~s}$ (traditional NSAID/ modified NSAID), which reflects the fold increase in potency, indicated that FBN was 15-fold more potent than flurbiprofen and up to 5-fold more potent than NO-flurbiprofen. A lower $\mathrm{IC}_{50}$ of FBN compared to NO-flurbiprofen in A-431 cells strongly suggests that the aromatic spacer may contribute to the strong growth suppressive properties of FBN either alone or by modifying delivery of NO. For further studies we focused on the effects of FBN on cellular kinetics such as proliferation, apoptosis, and cell cycle.

\section{FBN affects proliferation and induces apoptosis}

Proliferation and apoptosis are two major parameters determining cellular mass. We examined the effects of FBN

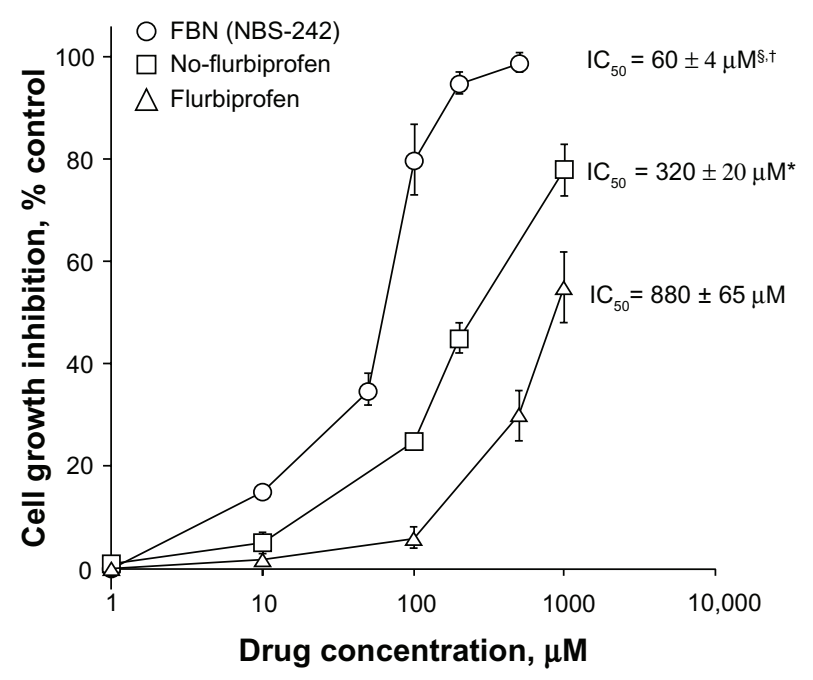

Figure 2 Inhibitory effect of FBN on A-43I cell growth.

Notes: Cells were treated with increasing concentrations of flurbiprofen, NO flurbiprofen, and FBN for 24 hours. Cell viability was determined by MTT assay as described in the Materials and methods section. Results are means \pm SEM of three different experiments performed in triplicate. $* P<0.05$ compared to flurbiprofen; ${ }^{\dagger} P<0.0$ l compared to flurbiprofen; ${ }^{\circledR} P<0.05$ compared to NO-flurbiprofen.

Abbreviations: $\mathrm{FBN}$, flurbiprofen benzyl nitrate; $I \mathrm{C}_{50}$, half maximal inhibitory concentration; NO, nitric oxide; NSAID, nonsteroidal anti-inflammatory drug; SEM, standard error of the mean. after 24 hours of treatment on these two parameters. PCNA is an index of the proliferative status of cells. FBN caused a concentration-dependent reduction of PCNA in A-431 cells from 10 to $75 \mu \mathrm{M}$ (Figure 3A). Compared to the control, the maximal antiproliferative activity of $\mathrm{FBN}$ was $15 \%$ at $75 \mu \mathrm{M}$ and remained relatively constant for increasing concentrations, suggesting that inhibition of proliferation may be a partial contributor to the growth inhibitory effect of FBN. On the other hand, the percentage of apoptotic cells, as measured by counting DAPI stained nuclei with apoptotic morphology, increased in a concentration dependent manner from 10 to $100 \mu \mathrm{M}$ FBN. At $75 \mu \mathrm{M}$, approximately $50 \%$ of the cells were apoptotic compared to the control (Figure 3A).

Since the induction of apoptosis may be mediated through the regulation of cell cycle, we examined the effect of FBN on cell cycle perturbations (Figure 3B). Cells were treated with various concentrations of FBN for 24 hours and their DNA content, as assessed by flow cytometric analysis, indicated that FBN-treated cells progressively accumulated in the $\mathrm{G}_{0} / \mathrm{G}_{1}$ phase; for example, at $100 \mu \mathrm{M}$ compared to untreated cells, the proportion of cells in the $\mathrm{G}_{0} / \mathrm{G}_{1}$ phase increased from $61 \%$ to $73 \%$, and concomitantly decreased the proportion of cells in the $\mathrm{G}_{2} / \mathrm{M}$ phase from $21 \%$ to $9 \%$. Collectively, our data indicate that FBN induces cell cycle arrest and apoptosis in A-431 cells.

\section{FBN targets components of the Wnt pathway and induces caspase-3}

According to the canonical Wnt/ $\beta$-catenin pathway, $\beta$-catenin translocates to the nucleus, interacting with TCF and modulating transcription of specific genes. We examined the effect of FBN on $\beta$-catenin protein levels in the cytoplasm and nucleus in these cells. FBN cleaved cytoplasmic and nuclear $\beta$-catenin as a function of concentration (Figure 4A and B), with substantial degradation at $75 \mu \mathrm{M}$ and $100 \mu \mathrm{M}$. In the cytoplasm, the functional consequence of reduced levels of $\beta$-catenin cleavage was examined by determining the cytoplasmic protein expression of cyclin D1. Cyclin D1 represents an early $\mathrm{G}_{1}$ phase cyclin and is a consequence of $\beta$-catenin/TCF-4 transcriptional activity. FBN at $25 \mu \mathrm{M}$ reduced cytoplasmic cyclin D1 levels and abrogated its expression completely at $75 \mu \mathrm{M}$ (Figure 4A). This abrogation was associated with $\beta$-catenin degradation observed at these concentrations. On the other hand, nuclear expression of cyclin D1, which is a result of protein export from the cytoplasm to the nucleus, was also strongly reduced (Figure 4B). Since these cells were asynchronously dividing, it is understandable that at 
A

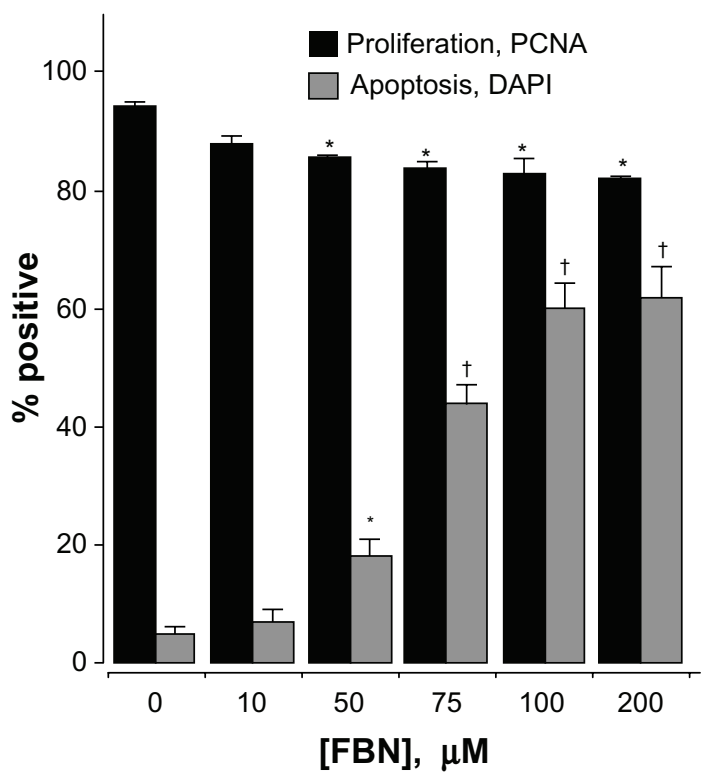

B

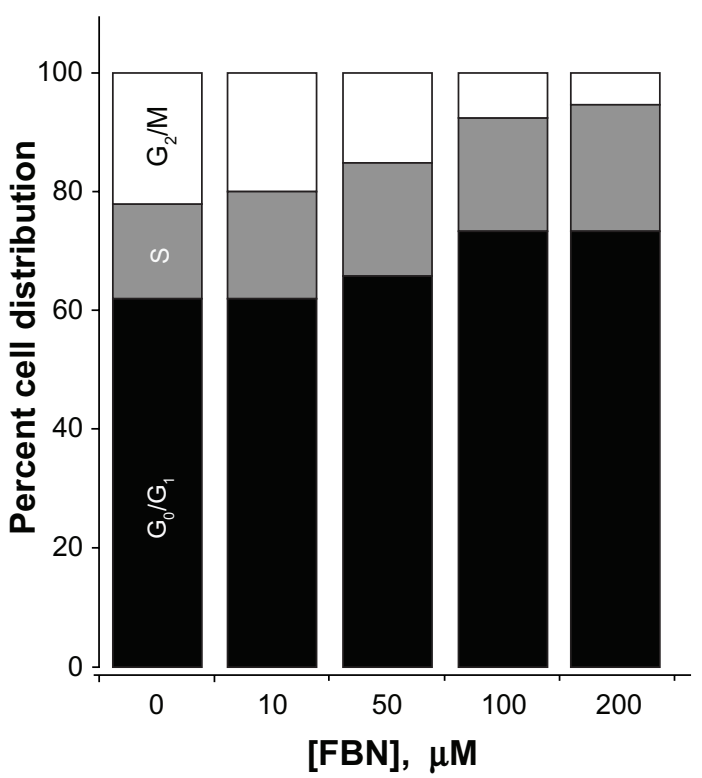

Figure 3 Effect of FBN on cell kinetics. $F B N$ causes $G_{0} / G_{1}$ cell cycle arrest, induces apoptosis, and inhibits proliferation. (A) A-43I cells were treated with FBN at the indicated concentrations for 24 hours followed by PCNA quantification for proliferation or DAPI staining of apoptotic nuclei and counting as described in the Materials and methods section. Results are mean \pm SEM of three different experiments. $* P<0.05$; ${ }^{\dagger} P<0.0$ I compared with untreated cells. (B) Asynchronous A-43I cells were treated with increasing concentrations of FBN as indicated for 24 hours.

Notes: The cells were then harvested and the percentage of the cells in the $G_{0} / G_{1}, S$, and $G_{2} / M$ phases were analyzed by flow cytometry. The populations of the cells ( $G_{0} / G_{1}$, $S$, and $G_{2} / M$ phases) are expressed as a percentage of the total cell population. Data shown here are from a representative experiment repeated two times with similar results, within $10 \%$ of each other.

Abbreviations: DAPI, 4,6-diamidino-2-phenylindole; FBN, flurbiprofen benzyl nitrate; PCNA, proliferating cell nuclear antigen; SEM, standard error of the mean.

any time of treatment with FBN cytoplasmic cyclin D1 and its nuclear levels will be affected. We further examined the protein level of TCF-4, the transcription factor in the nucleus that binds to $\beta$-catenin. FBN completely reduced the expression of TCF-4 at $75 \mu \mathrm{M}$. Thus, FBN targets the two major elements of the Wnt pathway, namely $\beta$-catenin and TCF-4. Our data demonstrate that $F B N$ induces $G_{1}$ cell cycle arrest, which agrees well with the marked downregulation of cyclin D1.

We also examined the activation of caspases by FBN since there was a strong induction of apoptosis in A-431 cells by DAPI staining as shown in Figure $3 \mathrm{~A}$. Caspase activation constitutes the hallmark of apoptotic detection and it is well known that $\beta$-catenin is a direct target of caspase- 3 activity. ${ }^{24}$ Therefore, the activation of caspase-3 was examined in the cytoplasm fraction of A-431 cells by performing immunoblotting detection for procaspase- 3 and its smaller cleaved fragment, signifying the activation of caspase-3. The appearance of activated caspase- 3 was observed initially at $50 \mu \mathrm{M} F B N$, followed by a substantial increase in activation at 75 and $100 \mu \mathrm{M}$ FBN, with simultaneous reduction in levels of procaspase-3 (Figure 4A). The activation of caspase- 3 coincided with the cleavage of $\beta$-catenin at 50 and $75 \mu \mathrm{M}$ suggesting that there is an association between the events.

\section{Discussion}

This study demonstrates the potential of the aromatic NO-releasing compound FBN against skin cancer of the nonmelanocytic type that is known to occur via constitutive activation of $\beta$-catenin/TCF signaling. We report, for the first time, the effects of an NO-releasing flurbiprofen that has an aromatic spacer. FBN is more potent than NO-flurbiprofen and flurbiprofen in inhibiting the growth of the A-431 skin cancer cell line.

The data suggest a possible link between the growth inhibitory effects of FBN and the $\beta$-catenin pathway as a potential target. Studies in recent years have suggested that $\beta$-catenin accumulation has been implicated in tumorigenesis in a wide variety of human cancers including skin cancer. ${ }^{3}$ These studies suggest, in essence, that degrading nuclear accumulation of $\beta$-catenin suppresses tumorigenesis. Our data show the possible molecular mechanism underlying the antigrowth effect of FBN. Taken together, these results suggest that the reduction of $\beta$-catenin expression by FBN may contribute to an antiproliferative mechanism in A-431 skin cancer cells. Others have shown that downregulation of $\beta$-catenin expression by accelerating its proteasomal degradation led to impaired cell proliferation and abolished the tumorigenic potential of these cells in the nude mice model. ${ }^{26}$ In this 


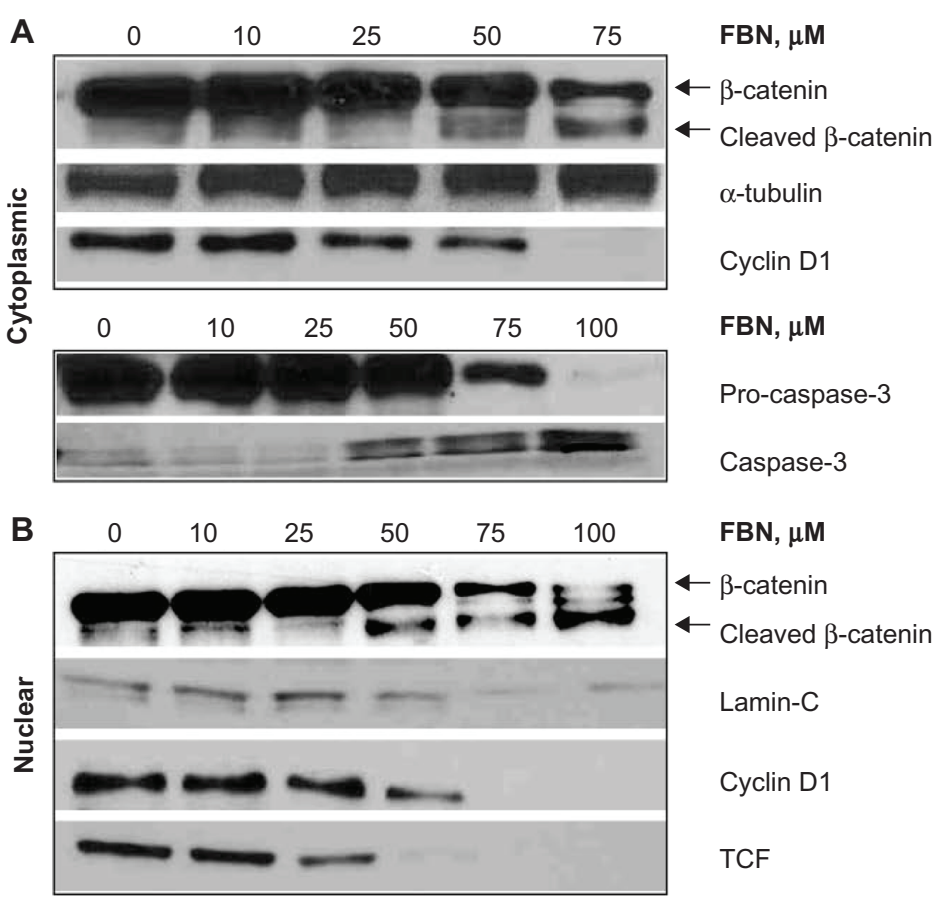

Figure 4 FBN degrades $\beta$-catenin, inhibits cyclin DI, and activates caspase-3.

Notes: A-43I cells were treated with FBN at the indicated concentrations for 24 hours followed by cytoplasmic and nuclear protein extraction. Proteins were detected by immunoblotting with specific antibodies. Results are representative of two independent experiments. The densitometry of the bands was within I5\% of each other.

Abbreviations: FBN, flurbiprofen benzyl nitrate; TCF, T-cell factor.

regard, the NSAID R-flurbiprofen was reported to show strong antiproliferative effects in vivo and in vitro. ${ }^{27}$ However, very high concentrations of this compound, such as $1000 \mu \mathrm{M}$ R-flurbiprofen, did not affect the protein level of $\beta$-catenin or induce its degradation. ${ }^{27} \mathrm{An}$ interesting future goal would be to determine whether proteolytic cleavage of $\beta$-catenin is simply an effect of apoptosis or induces the apoptotic program. The versatile functions of $\beta$-catenin within the interplay of cell growth and cell death will be an interesting aspect for future studies on FBN.

Since the only difference between NO-flurbiprofen and FBN is the linker joining the NO-releasing group to the NSAID flurbiprofen, it may be concluded that the enhanced potency observed with FBN may be due to the aromatic linker alone, or the way in which $\mathrm{NO}$ is delivered or a combination of both.

Previous work by us on the structure-activity properties of NO-aspirin had indicated that $\mathrm{NO}$ was pivotal for its anticancer effects. ${ }^{22}$ However, careful re-examination regarding the contribution to the overall biological effect of each of the three structural components of NO- acetylsalicylate (ASA) in which the spacer joining the ASA to the NO-releasing moiety was aromatic, led us and others to conclude that the NO-releasing moiety was not required for the observed biological effects. Rather, the spacer was responsible for the biological actions of NO-aspirin, with the NO-releasing moiety acting as a leaving group that facilitated the release and activation of the spacer to a quinone methide intermediate which acted as a powerful electrophile. ${ }^{28-30}$ Here, we have NO-flurbiprofen which was $\sim 2.8$-fold more potent than its parent compound flurbiprofen in inhibiting the growth of A-431 cells and FBN which was $\sim 15$-fold more potent. On this basis, we may cautiously conclude that with FBN we may have two effects, one as a result of released NO and one due to an active aromatic linker.

Finally, FBN is able to reduce PCNA levels, which is a polymerase accessory protein detected in a cell-cycledependent manner, ${ }^{31}$ with a marked downregulation of cyclin D1. The cyclin D1 proto-oncogene is an important regulator of $\mathrm{G}_{1}$ to $\mathrm{S}$ phase transition in numerous cell types from diverse tissues. This series of events results in a $G_{1}$ phase arrest of the cell cycle, which is an irreversible process that ultimately results in the apoptotic death of cancer cells.

In conclusion our data establish a strong inhibitory effect of FBN in A-431 human epidermoid carcinoma cells, an effect that is modulated through parameters important in determining cellular mass. FBN is more potent than NO-flurbiprofen and flurbiprofen in the inhibition of cell proliferation. Activation of caspase- 3 is associated with degradation of $\beta$-catenin and reduction in cyclin D1 levels, 
suggesting that FBN has potential as a chemotherapeutic agent against NMSC.

Two major aspects constitute future directions for this study. First, at the mechanistic level, the degradation of $\beta$-catenin by FBN merits further investigation regarding the sequence of events in relation to caspase activity. A second focus is the potential of FBN in topical treatment regimens, which are generally considered to be better alternatives for nonmelanoma skin cancer in minimizing systemic exposure while achieving high local concentrations of the drug. We are currently formulating hydrogel-delivering systems for local application of FBN.

\section{Acknowledgments}

This work was supported in part by NIH grant R24 DA018055. The funding agency had no role in the study design, collection, analysis, and interpretation of data; in the writing of the manuscript; or in the decision to submit the manuscript for publication.

\section{Authors' contributions}

Participated in research design: NN, KK; conducted experiments: NN, LJ, XL; performed data analysis: NN, LJ, XL, $\mathrm{KK}$; wrote or contributed to the writing of the manuscript: NN, LJ, XL, KK.

\section{Disclosure}

The authors report no conflicts of interest in this work.

\section{References}

1. American Cancer Society. Cancer Facts and Figures 2010. Atlanta: American Cancer Society; 2010. Available from: http://www.cancer.org/ acs/groups/content/@epidemiologysurveilance/documents/document/ acspc-026238.pdf. Accessed March 26, 2013.

2. Tataroglu C, Karabacak T, Apa DD. Beta-catenin and CD44 expression in keratoacanthoma and squamous cell carcinoma of the skin. Tumori. 2007;93(3):284-289.

3. Doglioni C, Piccinin S, Demontis S, et al. Alterations of beta-catenin pathway in non-melanoma skin tumors: loss of alpha-ABC nuclear reactivity correlates with the presence of beta-catenin gene mutation. Am J Pathol. 2003;163(6):2277-2287.

4. El-Bahrawy M, El-Masry N, Alison M, Poulsom R, Fallowfield M. Expression of beta-catenin in basal cell carcinoma. $\mathrm{Br} J$ Dermatol. 2003;148(5):964-970.

5. Bhatia N, Spiegelman VS. Activation of Wnt/beta-catenin/Tcf signaling in mouse skin carcinogenesis. Mol Carcinog. 2005;42(4):213-221.

6. Thun MJ, Henley SJ, Patrono C. Nonsteroidal anti-inflammatory drugs as anticancer agents: mechanistic, pharmacologic, and clinical issues. J Natl Cancer Inst. 2002;94(4):252-266.

7. Baron JA. Epidemiology of non-steroidal anti-inflammatory drugs and cancer. Prog Exp Tumor Res. 2003;37:1-24.

8. Benamouzig R, Deyra J, Martin A, et al. Daily soluble aspirin and prevention of colorectal adenoma recurrence: one-year results of the APACC trial. Gastroenterology. 2003;125(2):328-336.

9. Sandler RS, Halabi S, Baron JA, et al. A randomized trial of aspirin to prevent colorectal adenomas in patients with previous colorectal cancer. N Engl J Med. 2003;348(10):883-890.
10. Rothwell PM, Price JF, Fowkes FG, et al. Short-term effects of daily aspirin on cancer incidence, mortality, and non-vascular death: analysis of the time course of risks and benefits in 51 randomised controlled trials. Lancet. 2012;379(9826):1602-1612.

11. Rothwell PM, Wilson M, Price JF, Belch JF, Meade TW, Mehta Z. Effect of daily aspirin on risk of cancer metastasis: a study of incident cancers during randomised controlled trials. Lancet. 2012; 379(9826):1591-1601.

12. Clouser MC, Roe DJ, Foote JA, Harris RB. Effect of non-steroidal anti-inflammatory drugs on non-melanoma skin cancer incidence in the SKICAP-AK trial. Pharmacoepidemiol Drug Saf. 2009;18(4):276-283.

13. Elmets CA, Viner JL, Pentland AP, et al. Chemoprevention of nonmelanoma skin cancer with celecoxib: a randomized, double-blind, placebo-controlled trial. J Natl Cancer Inst. 2010;102(24):1835-1844.

14. Curiel-Lewandrowski C, Nijsten T, Gomez ML, Hollestein LM, Atkins MB, Stern RS. Long-term use of nonsteroidal anti-inflammatory drugs decreases the risk of cutaneous melanoma: results of a United States case-control study. J Invest Dermatol. 2011;131(7):1460-1468.

15. Bjorkman DJ. Current status of nonsteroidal anti-inflammatory drug (NSAID) use in the United States: risk factors and frequency of complications. Am J Med. 1999;107(6A):3S-8S; discussion 8S-10S.

16. Fitzgerald GA. Coxibs and cardiovascular disease. $N$ Engl $J$ Med. 2004;351(17):1709-1711.

17. Scheiman JM, Fendrick AM. Summing the risk of NSAID therapy. Lancet. 2007;369(9573):1580-1581.

18. Davies NM, Røseth AG, Appleyard CB, et al. NO-naproxen vs naproxen: ulcerogenic, analgesic and anti-inflammatory effects. Aliment Pharmacol Ther. 1997;11(1):69-79.

19. Wallace JL, Reuter B, Cicala C, McKnight W, Grisham MB, Cirino G. Novel nonsteroidal anti-inflammatory drug derivatives with markedly reduced ulcerogenic properties in the rat. Gastroenterology. 1994;107(1):173-179.

20. Fiorucci S, Santucci L, Gresele P, Faccino RM, Del Soldato P, Morelli A. Gastrointestinal safety of NO-aspirin (NCX-4016) in healthy human volunteers: a proof of concept endoscopic study. Gastroenterology. 2003;124(3):600-607.

21. Fiorucci S, Santucci L, Wallace JL, et al. Interaction of a selective cyclooxygenase-2 inhibitor with aspirin and NO-releasing aspirin in the human gastric mucosa. Proc Natl Acad Sci U S A. 2003; 100(19):10937-10941.

22. Kashfi K, Borgo S, Williams JL, et al. Positional isomerism markedly affects the growth inhibition of colon cancer cells by nitric oxidedonating aspirin in vitro and in vivo. $J$ Pharmacol Exp Ther. 2005; 312(3):978-988

23. Rigas B, Kashfi K. Nitric-oxide-donating NSAIDs as agents for cancer prevention. Trends Mol Med. 2004;10(7):324-330.

24. Nath N, Labaze G, Rigas B, Kashfi K. NO-donating aspirin inhibits the growth of leukemic Jurkat cells and modulates beta-catenin expression. Biochem Biophys Res Commun. 2005;326(1):93-99.

25. Penning TD, Talley JJ, Bertenshaw SR, et al. Synthesis and biological evaluation of the 1,5-diarylpyrazole class of cyclooxygenase-2 inhibitors: identification of 4-[5-(4-methylphenyl)-3-(trifluoromethyl)-1H-pyrazol1-yl]benze nesulfonamide (SC-58635, celecoxib). J Med Chem. 1997; 40(9):1347-1365.

26. Cong F, Zhang J, Pao W, Zhou P, Varmus H. A protein knockdown strategy to study the function of beta-catenin in tumorigenesis. $B M C$ Mol Biol. 2003;4:10.

27. Maier TJ, Janssen A, Schmidt R, Geisslinger G, Grösch S. Targeting the beta-catenin/APC pathway: a novel mechanism to explain the cyclooxygenase-2-independent anticarcinogenic effects of celecoxib in human colon carcinoma cells. FASEB J. 2005;19(10):1353-1355.

28. Kashfi K, Rigas B. The mechanism of action of nitric oxide-donating aspirin. Biochem Biophys Res Commun. 2007;358(4):1096-1101.

29. Dunlap T, Chandrasena RE, Wang Z, Sinha V, Wang Z, Thatcher GR. Quinone formation as a chemoprevention strategy for hybrid drugs: balancing cytotoxicity and cytoprotection. Chem Res Toxicol. 2007; 20(12):1903-1912. 
30. Hulsman N, Medema JP, Bos C, et al. Chemical insights in the concept of hybrid drugs: the antitumor effect of nitric oxide-donating aspirin involves a quinone methide but not nitric oxide nor aspirin. $J \mathrm{Med}$ Chem. 2007;50(10):2424-2431.
31. Hsieh T, Halicka D, Lu X, et al. Effects of resveratrol on the $\mathrm{G}(0)-\mathrm{G}(1)$ transition and cell cycle progression of mitogenically stimulated human lymphocytes. Biochem Biophys Res Commun. 2002; 297(5):1311-1317.

\section{Publish your work in this journal}

Drug Design, Development and Therapy is an international, peerreviewed open-access journal that spans the spectrum of drug design and development through to clinical applications. Clinical outcomes, patient safety, and programs for the development and effective, safe, and sustained use of medicines are a feature of the journal, which has also been accepted for indexing on PubMed Central. The manuscript management system is completely online and includes a very quick and fair peer-review system, which is all easy to use. Visit http://www.dovepress.com/testimonials.php to read real quotes from published authors.

Submit your manuscript here: http://www.dovepress.com/drug-design-development-and-therapy-journal 